\title{
Density Dependant Sex Change in Northern Shrimp, Pandalus borealis, on the Scotian Shelf
}

\author{
Peter Koeller, Robert Mohn and Marianne Etter \\ Department of Fisheries and Oceans, Bedford Institute of Oceanography \\ P. O. Box 1006, Dartmouth, Nova Scotia B2Y 4A2, Canada
}

\begin{abstract}
We investigated factors affecting sex change in the Pandalid shrimp Pandalus borealis on the Scotian Shelf. Transition from male to female occurred at different sizes and ages, and could not be related to a minimum size or age. Our data did not show a positive relationship between abundance of older females and shrimp size at sex transition, nor a negative relationship between male:female sex ratio and shrimp size at transition, that would be expected if the population was compensating for decreases in reproductive capacity as predicted by sex allocation theory. Size at transition was inversely related to female density, which was attributable to density dependent growth affecting all stages. Density dependant growth also appeared to explain previously reported results which had been used to support sex allocation theory. Density was the most important factor determining individual growth at high densities while at low densities other factors, including temperature, were also an important determinant of growth. We conclude that a decrease in the size at transition can be indicative of a healthy, as well as a declining stock, and must be fully understood before it can be used as an indicator of stock status. Possible alternative mechanisms for regulating sex change in Pandalids are discussed.
\end{abstract}

Key words: density dependant growth, Pandalid shrimp, sex change, sex allocation theory

\section{Introduction}

Northern shrimp Pandalus borealis is the target of important fisheries in the North Atlantic and North Pacific. These shrimp are protandric hermaphrodites, becoming mature females after spending $1-4$ years as functional males, depending on geographic location and local conditions (Shumway et al., 1985). Pandalid shrimp have been used as a "model" organism to further theories about the environmental, genetic and evolutionary mechanisms determining sex allocation. Theories on the adaptive value of protandry range from the increased reproductive efficiency of small males and large females (Warner, 1974) to no adaptive value, or even negative effects in some situations (Carpenter, 1978). While protandry is undoubtedly important in the population dynamics of the species, the factors which determine sex change remain obscure and controversial. Yet a change in the size at transition is often used as an indicator of stock health (see for example Armstrong et al., 1999) and is interpreted according to the sex allocation theory (e.g. Charnov et al., 1978), that a decrease in size at transition implies a decreasing stock (the population is compensating for decreasing reproductive capacity by decreasing the size at which they become females).
Charnov et al. (1978) provided empirical evidence that Pandalus jordani off Oregon and Northern California, USA actively alters the age at which it changes sex in response to changes in age composition of the population, in accordance with sex allocation theory and genetic models. They found a negative correlation between the female proportion of $P$. jordani first-time breeders (also called primary females, or females that had not previously been males) and the ratio of older breeders (both males and females) to first breeders. In other words, as the proportion of older breeders decreased, the population compensated for the decrease in reproductive capacity by eliminating the male phase for part of the population. Charnov (1981) argued that the increased numbers of primary females of $P$. borealis in the Skagerrak observed by Jensen (1967) were results of fishery induced decreases in older breeders according to sex allocation theory. Charnov and Anderson (1989) proposed that, at a single location, shrimp have neither a fixed size nor age at sex change and, as further evidence to the age-based analysis presented in Charnov et al. (1978), showed that annual fluctuations in size distribution (as measured by the mean size of breeding individuals in the population) was positively correlated to the size at sex change. In other words, 
as the mean size of breeding animals decreased, due to increased mortality of older breeders through fishing or environmental influences, the size at sex change also decreased. On the other hand, Bergström (1997) found no evidence that annual variation in age/size structure affected the time at sex change in P. borealis from enclosed fjordic populations; however, his study encompassed only a short time series. In view of the controversy surrounding size/age of sex change in Pandalid shrimp and its potential use as an indicator of stock status, we examined factors influencing sex change in the P. borealis stock on the Scotian Shelf. Our working hypotheses were that sex change in this stock is regulated by the abundance of mature females, by sex ratio, or by the population size distribution as suggested by Charnov and Anderson (1989). The Scotian Shelf is an excellent area for such a study as it harbours a small, isolated stock that has shown relatively high cyclical fluctuations in abundance and low exploitation rates $(<10 \%$, Koeller et al., MS 1997).

\section{Materials and Methods}

Shrimp surveys were conducted on the eastern Scotian Shelf shrimp "holes" (Fig. 1) by the RV E. E. Prince of the Department of Fisheries and Oceans, Canada (DFO) in spring (April-May) and autumn (October-November) in 1982-88 inclusive, and in June 1995-97 by commercial shrimp trawlers during DFOindustry co-operative surveys. For all surveys, at least 45 thirty-minute trawl sets were conducted during daylight hours, allocated approximately equally among the main shrimp holes (Canso, Louisbourg and Misaine). In 1995-97 additional coverage (approx. 15 sets annually) was obtained for the inshore shrimp grounds (The Noodles). Stations were allocated randomly within each of the four areas except in Misaine Hole, where the same stations were always fished due to difficulties finding trawlable bottom. RV E.E. Prince used the same trawl (Yankee 36 shrimp trawl, $40 \mathrm{~mm}$ codend mesh) throughout its series, while three different commercial vessel/trawl combinations

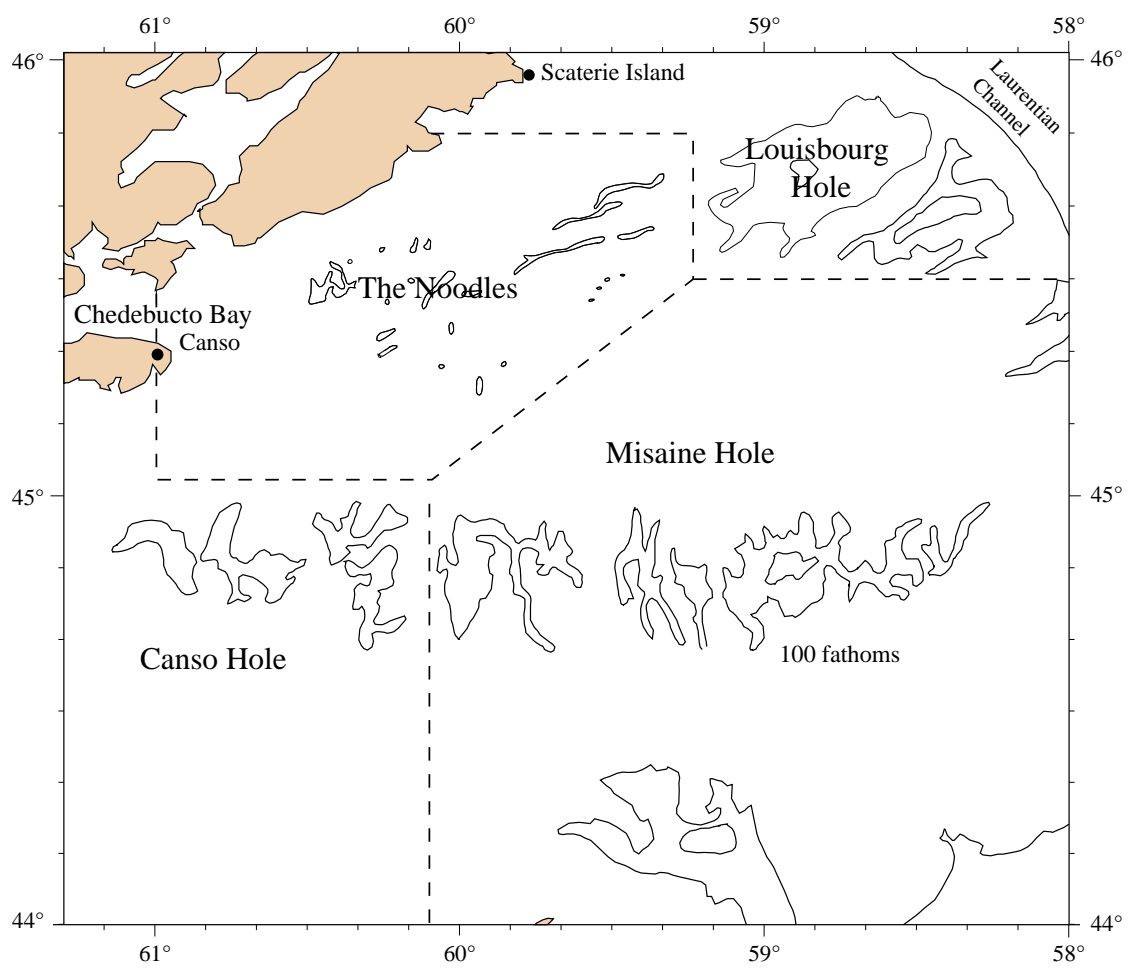

Fig. 1. Study area, including the three main shrimp "holes" (Canso, Louisbourg and Misaine) and the inshore area (The Noodles) surveyed by DFO's RV E.E. Prince from 1982-88 and by commerical vessels during 1995-97 DFOindustry surveys. The shrimp holes are areas deeper than 100 fathoms defined by the dashed lines. The Noodles are defined by all areas and depths within the dashed line. 
were used from 1995-97, requiring comparative fishing experiments in 1996 and 1997 to allow comparison with the 1995 vessel in terms of catch rates and size selectivities (Koeller et al., MS 1996, MS 1997). Since there was no comparative fishing data between vessels/ gears used in 1982-88 and 1995-97, it was not possible to directly compare these two series in terms of densities, but because the same codend mesh size (40 $\mathrm{mm}$ ) was used for both series, selectivities were assumed to be reasonably similar. Long term shrimp abundance trends spanning these two periods were determined from commercial shrimp trawler catch and effort information available from logbooks (Koeller et al., MS 1997).

A sample of approximately 500 animals was collected from each station and frozen for determinations of carapace length, individual weights and sex/ developmental stage. Carapace lengths were measured to the nearest $0.1 \mathrm{~mm}$. These measurements were subsequently aggregated into $1-\mathrm{mm}$ cells for further analyses. Shrimp were identified according to the methods of Allen (1959) and McCrary (1971) as immature, male, transitional, primiparous or multiparous females, with transitional and primiparous animals representing the new females of that year. Transitional animals were rare in autumn surveys because most had completed sex change, consequently only spring surveys were used in analyses requiring summarized data on transitionals. Because transitional animals were identified, it was possible to determine actual mean sizes at transition rather than size at $50 \%$ female. Densities in numbers per $\mathrm{m}^{2}$ from each set were calculated from the total weight caught, mean individual shrimp weights from a subsample, and the area swept by the trawl. Swept area was calculated from the distance traveled during the tow and the wingspread of the trawl determined from trawl design specifications (1982-88) or actual measurements during the set using a SCANMAR net measuring device (1995-97). Bottom temperatures on the shrimp grounds during the study period were collected on the shrimp surveys described above and groundfish surveys (July, 1982-98) using a variety of instrumentation including reversing thermometers, CTDs and continuous temperature recorders. Temperature observations during the 1982-88 period were not taken at every set during some surveys, so analysis involving temperature were limited to a subset of those observations where temperatures were available.

To determine if the density of older (multiparous) females was related to shrimp size at transition, we correlated the mean size of transitional animals in each of three main areas against the abundance of multiparous females for the 1982-88 spring survey data only, as the 1995-97 series were not comparable in terms of abundances because of gear changes. Because codend sizes were the same for both survey series we regressed the mean sizes of transitionals against the mean sizes of breeding adults (males and females combined) as in Charnov and Anderson (1989), using mean sizes per area for both survey series as well as mean sizes per individual set location for selected years. Sex ratios were determined as the number of identified males divided by the number of females, where the number of females included the number of transitionals i.e. animals that would turn female that year. Comparisons of densities between developmental stages were made on the assumption that there is relatively little exchange between shrimp holes on the Eastern Scotian Shelf. While there may be considerable planktonic larval exchange between areas, survey results suggest that this assumption holds true for older stages (Koeller, 1996). Since primary females are rare on the Scotian Shelf, changes in their abundance relative to females that have changed sex cannot be determined as in Charnov et al. (1978), so the size based analysis presented in Charnov and Anderson (1989) was used.

\section{Results}

In general, average water temperatures taken during shrimp (April-June) and groundfish (July) surveys on the eastern Scotian Shelf shrimp grounds decreased throughout the 17-year study period (198298), particularly during the RV E.E. Prince survey series (1982-88). Except for Louisbourg Hole, water temperatures during the recent DFO-industry survey series (June, 1995-97) were among the coldest recorded (Fig. 2). Louisbourg Hole generally had the warmest water of the 4 surveyed shrimp areas, probably due to its close proximity to the warm, deep water of the Laurentian Channel.

Biomass trends from shrimp surveys were in general agreement with the catch-per-unit-effort index from commercial trawlers, the only continuous index of abundance throughout the study period (Fig. 3). Abundance decreased during the early-1980s, bottomed out in the mid-1980s, and increased thereafter. In summary, the $1982-88$ period was one of both decreasing temperatures and abundance, while high abundance and continuing low temperatures characterize the 1995-97 period. 




Fig. 2. Mean bottom temperatures in the offshore shrimp holes $(>100$ fathoms) and the inshore (The Noodles) area from shrimp surveys (April-June 1982-88; 1995-98) and from DFO groundfish surveys conducted during July 1982-97.

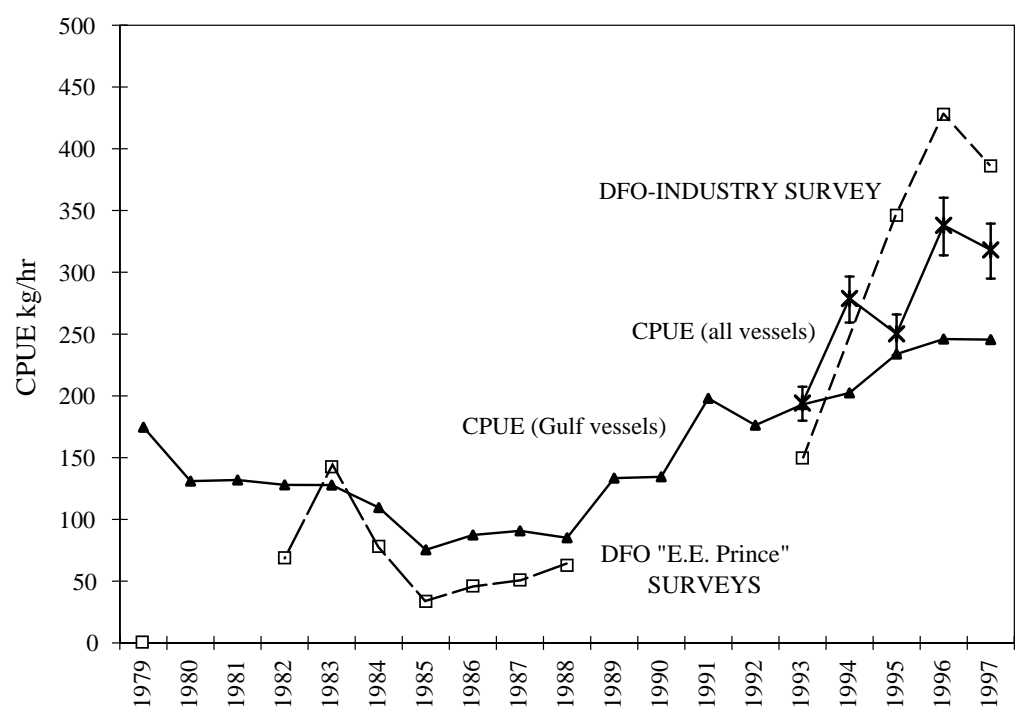

Fig. 3. Shrimp abundance on the eastern Scotian Shelf shrimp grounds (all areas) as catch-per-unit-effort (cpue-kg/hour) from commercial fishing vessel logs, DFO surveys and DFO-industry surveys. Two series of commercial cpue data are shown, including one for vessels based in the Gulf of St. Lawrence which spans the entire study period, and one for all vessels which covers the recent period of expansion of the fishery and shows $95 \%$ confidence limits of the estimates. Note that a DFO-industry survey conducted in 1993 provided abundance data but shrimp sexual development stages were not determined. 
There was a highly significant correlation between size at transition and the mean size of breeding adults (males and females) throughout the period when shrimp surveys were conducted (Fig. 4A). Fig. 4B-D also shows that there were significant correlations between these parameters within years. Most observations from Louisbourg Hole were in the upper right quadrant, consistent with the warmer temperatures and expected faster growth rates in this area. Mean lengths increased for all stages during 1982-88 (Fig. 5A-C). It should be noted, however, that transitionals exhibited a "growth spurt" i.e. they increased in size much more rapidly than either males or females between 1982 and 1988 (Fig. 5B, D). Sex ratios did not show a trend (Fig. $5 \mathrm{E})$. Mean carapace lengths for each stage remained high during the 1995-97 period (Fig. 6). Note that there were 2-3 length modes (ages) during the 1982-88 period and 3-5 modes during the 1995-97 period. This indicates that males, transitionals and females in the recent period were as large or larger than in the mid- 1980s but were a year older, and consequently growth was slower. This was confirmed by modal analysis of 1988 and 1995 data (Fig. 6, inset).

The relationship between abundance of older (multiparous) females and the mean size of transitionals (Fig. 7A) was significant at $p<0.05$, with a negative slope. The relationship between overall mean carapace length (i.e. all stages) and total density for both spring and autumn surveys (annual means for each area, Fig. 7B) was also highly significant, as were correlations between carapace length and density for each fishing set of the 1982-88 and 1995-97 survey series (Fig. 8 A,B). R-squared values increased when the shrimp holes were included in a multiple regression, with density, temperature and area explaining nearly $50 \%$ of the variance in the model in the 1995-97 series (Table 1). The 1982-88 series also showed that each individual survey contributed significantly to the variance, because some surveys
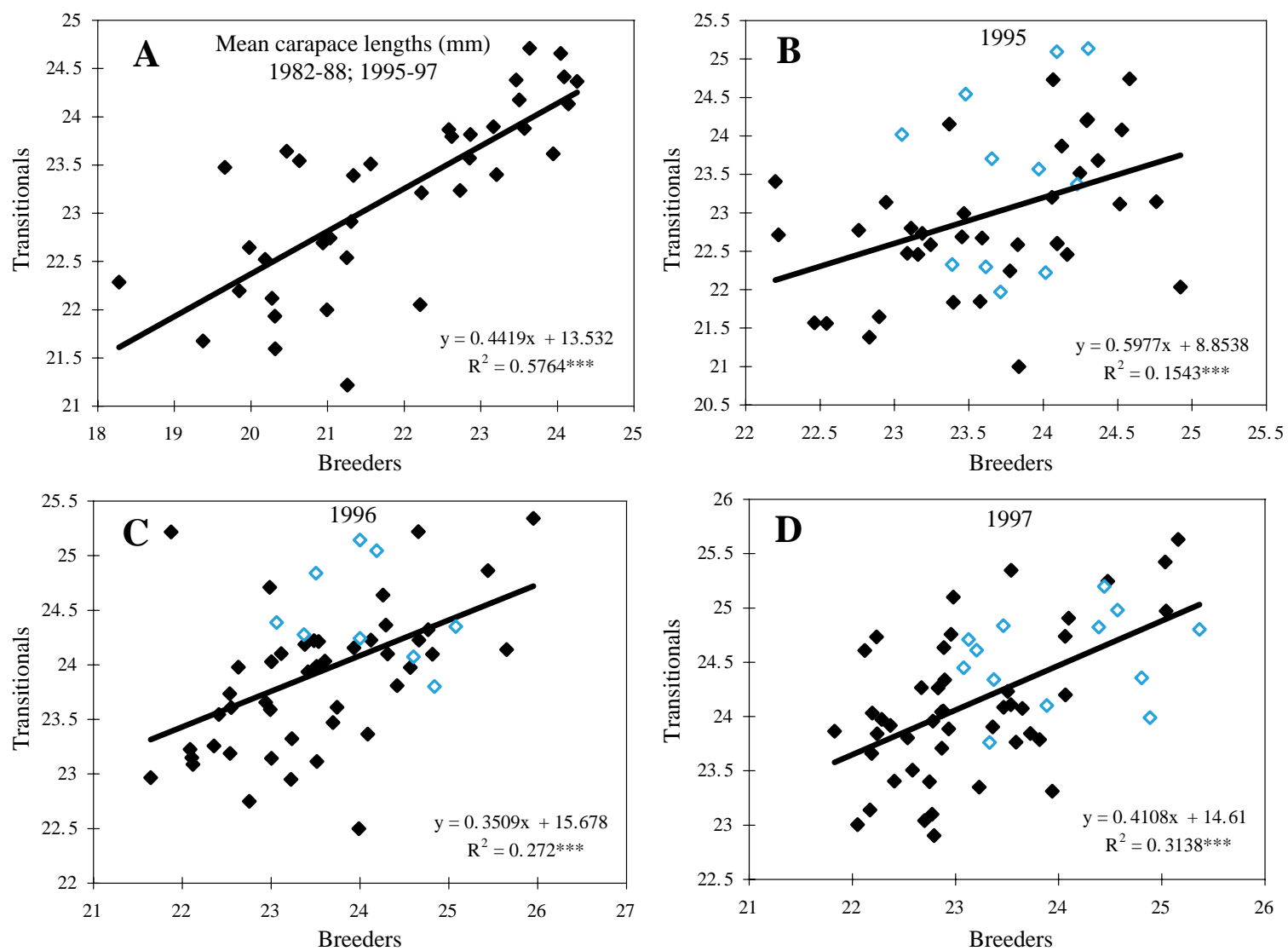

Fig. 4. Mean carapace lengths of transitional shrimp versus breeders (males and females) for A) annual means in each area for all surveys, and set means for the B) 1995, C) 1996, and D) 1997 surveys. The open markers in B-D represent sets conducted in Louisbourg Hole. 

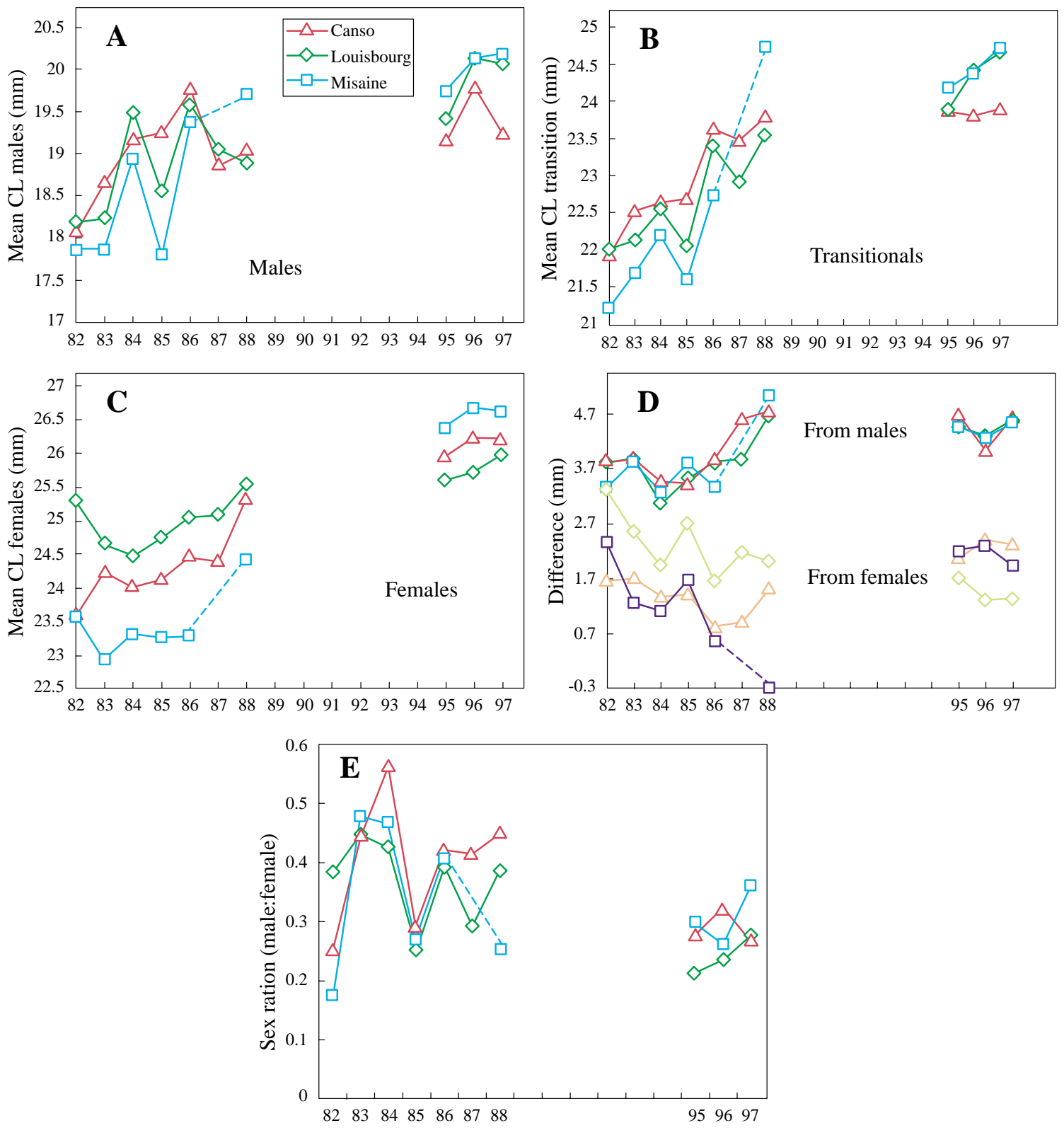

Fig. 5. Annual mean carapace lengths in the three shrimp holes for, A) males, B) transitionals and C) females. D) Difference between mean CL of transitionals and males and females in the three holes. E) sex ratios (males:females) in the three holes.

showed a stronger relationship between carapace length and density. It was noted that in both 1982-88 and 1995-97 periods, density was more important than temperature in explaining the variance around the model when all densities were included in the analysis. However at low densities $\left(<1\right.$ animal per $\left.\mathrm{m}^{2}\right)$ in the 199597 data, (Table 1) temperature was more important, and the correlation was positive. The characteristic decreasing pattern of residuals for the length versus density scatter diagram (Fig. 8A and B) also indicated that density becomes increasingly important as a determinant of carapace length (i.e. growth) as density increases, while other factors, including temperature, become more important as density decreases. There 


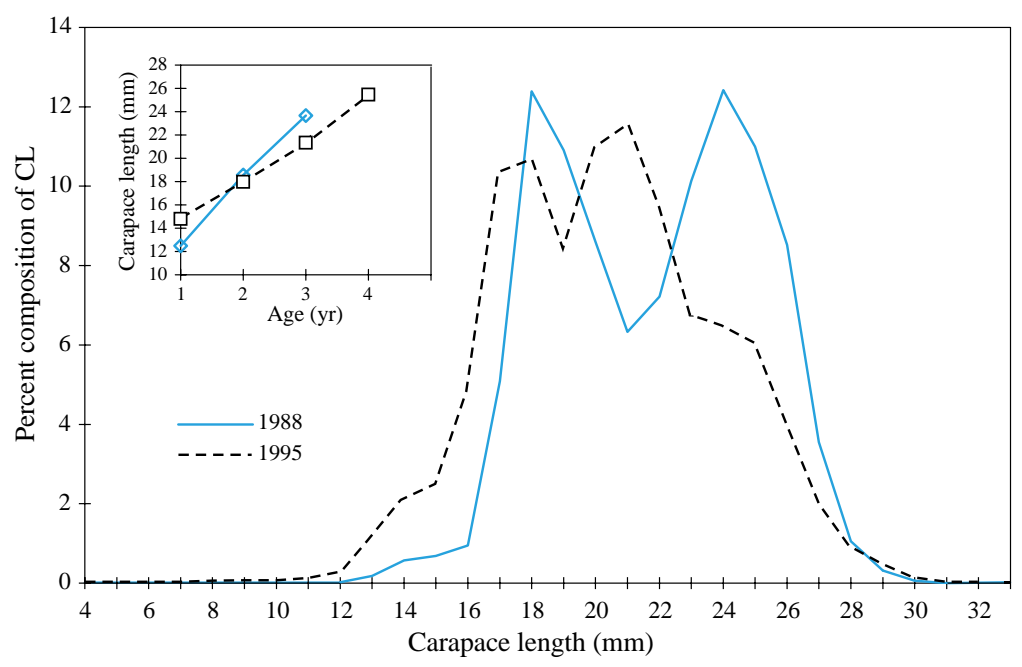

Fig. 6. Length frequencies from the last year of the 1982-88 survey series and the first year of the 1995-97 series, and results of modal analysis from the same data (inset).

was no discernable relationship between sex ratio and size at transition, summarized by year and area (Fig. 9A) or on an individual set basis (Fig. 9B).

\section{Discussion}

The Scotian Shelf shrimp stock underwent significant changes in abundance and experienced large environmental differences during the study period, which affected growth and size at transition. Shrimp abundance changed by a factor of 4 , which has been largely attributed to opposite trends in predator abundance, especially cod (Koeller, 2000). Densities during periods of abundance exceeded 4 animals $/ \mathrm{m}^{2}$, which decreased growth, presumably due to intraspecific competition. We found that densities were most important in determining growth at the highest densities, while at lower densities other factors, especially temperature, were also involved. Decreases in temperatures in 1982-88 would have decreased growth rates and size at transition, while decreasing densities would have done the opposite due to compensatory effects. In the recent period (1995-97), both high densities and low temperatures would have tended to decrease growth rates and size at transition. Clearly, the impact of at least temperature and density must be considered when evaluating the cause of a change in size at transition. If size at transition alone had been used as an indicator of stock health, and its change during 1982-88 interpreted according to sex allocation theory, it would have been erroneously concluded that shrimp were increasing in abundance during that period.

As in Charnov and Anderson (1989) we found a highly significant positive correlation between size at transition and the mean size of breeding adults (males and females). Charnov and Anderson (1989) presented this as evidence that the size at transition "tracks" annual changes in the population size distribution according to sex allocation theory. However, we also found significant correlations between these parameters within years, indicating that these relationships involved small scale spatial differences in growth, rather than temporal population wide adjustments for lost reproductive capacity (Fig. 4). This was confirmed by the faster growth rates in areas with warmer temperatures (Fig. 4) and the demonstration of density dependant effects on a set by set basis (Fig. 8).

Our results show that the size at sex change is inversely related to the density of older females (Fig. 7). This is opposite to what is predicted by sex allocation theory and indicates that the Scotian Shelf shrimp population did not decrease size at sex change to compensate for decreases in reproductive potential. Density dependent growth affected all sizes and stages, not just transitionals. Growth increased for all stages during the period of decreasing densities during 198288. In addition, we found no evidence of a negative relationship between the male:female sex ratio and size at transition as predicted by sex allocation theory. 

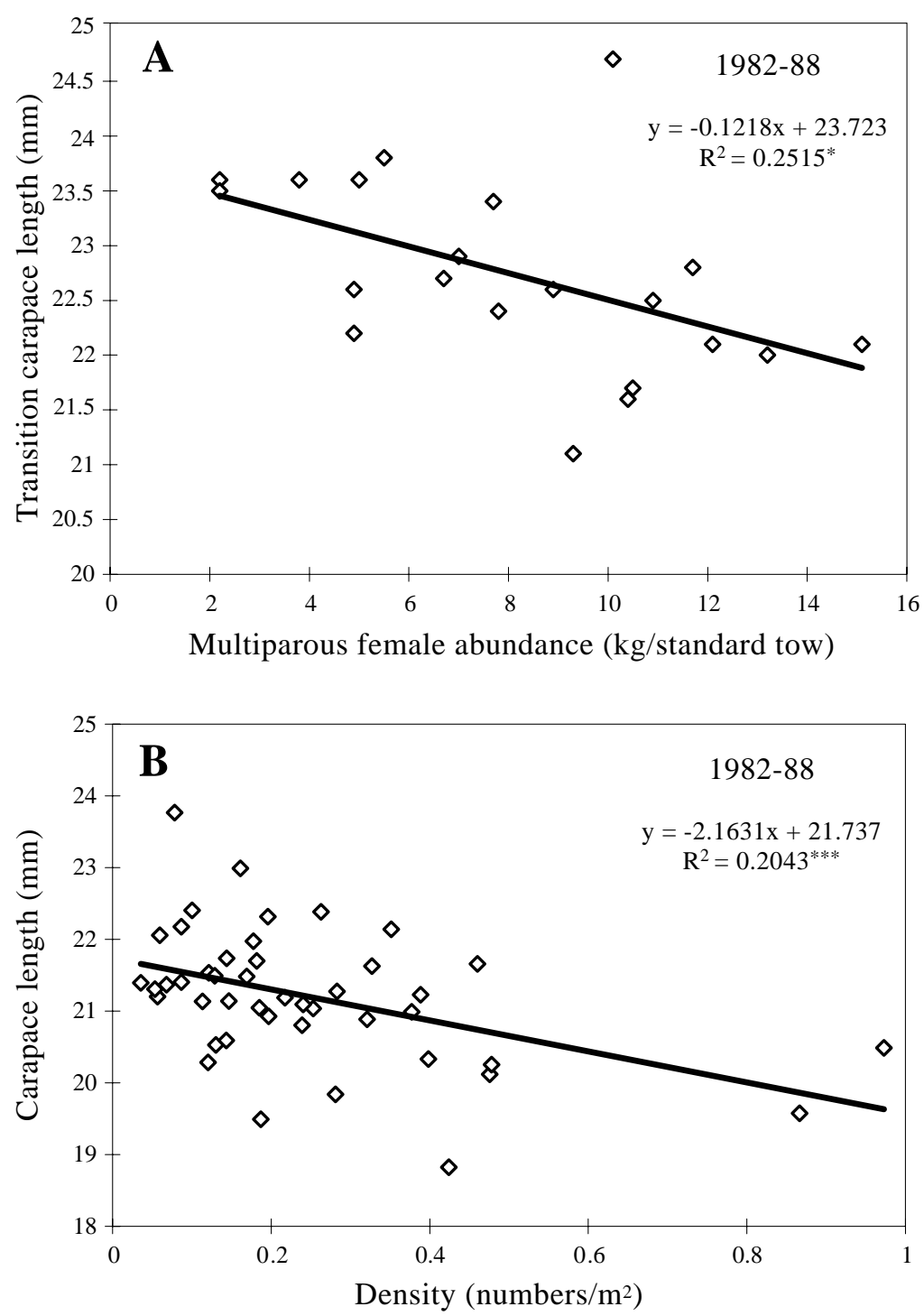

Fig. 7. A) Annual mean carapace length of transitionals verses multiparous female abundance indices ( $\mathrm{kg} / \mathrm{standard}$ tow) in each shrimp fishing hole for the 1982-88 series. B) Annual mean carapace length versus density (numbers $/ \mathrm{m}^{2}$ ) in each fishing hole for the 1982-88 series.

The present study indicates that the results presented by Charnov and Anderson (1989), as evidence that Pandalid shrimp actively change their size at sex change according to sex allocation theory, can also be explained as interannual and local differences in growth rates. Bergström (1997) also rejected Charnov and Anderson's hypothesis, however, his conclusions were based on negative results from a short (4 years) time series with limited spatial coverage.
The adaptive advantage to Pandalids of actively changing size at sex change as described by Charnov (1979) is that the loss of egg production due to increased mortality of females is offset by decreased size at sex change. The negative correlation with density we observed has the same result in terms of egg production, without the need to assume that males actively regulate their length or age at sex change according to the density of females in their vicinity. Since the average size of females increases as their 


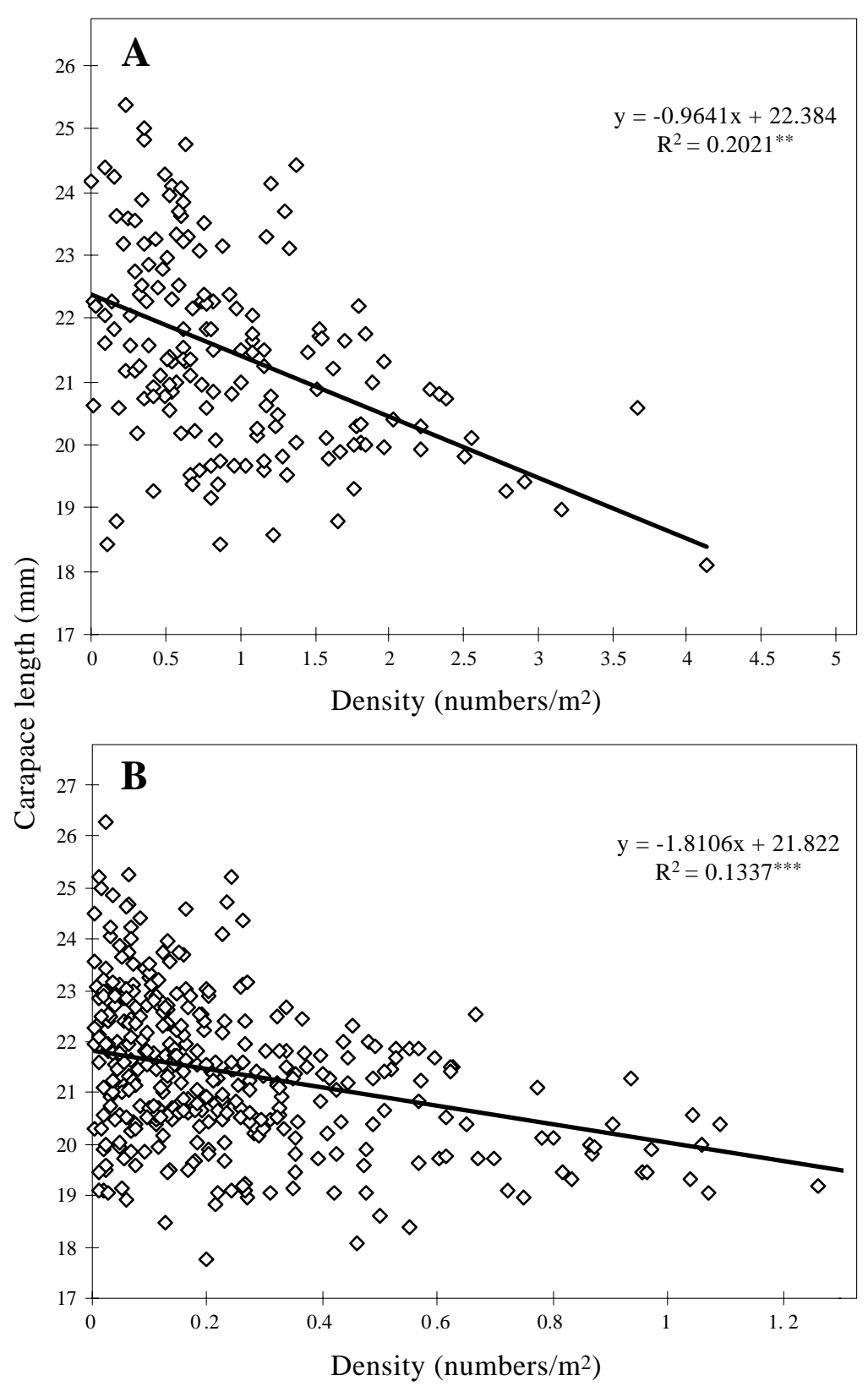

Fig. 8. Mean carapace length versus density at each set for the A) 199597 and B) 1982-88 survey series.

density decreases and fecundity is positively correlated to size (Shumway et al., 1985), average egg production per female still increases with decreasing female densities. Our results do not refute sex allocation theory as described by Charnov (1979), but they do suggest that some Pandalid stocks, especially those which do not normally produce primary females, may be inappropriate models for demonstrating its principles.
The advantage of protandry as proposed by Warner (1974) is that less energetically demanding sperm are produced by small animals, while the more energetically demanding eggs are produced by the largest members of the population. In addition, the number of eggs produced is directly related to size of females, so a larger female has a selective advantage. The observed "growth spurt" of transitionals on the Scotian Shelf suggests that transitionals are a growth 
TABLE 1. Multiple regression analysis of mean carapace length versus density, temperature, area and cruise for each fishing set of the 1982-88 and 1995-97 survey series.

\begin{tabular}{|c|c|c|c|c|c|c|}
\hline & & df & SS & Mean Sq & F Value & $\operatorname{Pr}(\mathrm{F})$ \\
\hline \multirow{6}{*}{$\begin{array}{l}1982-88 \\
\text { all data }\end{array}$} & density & 1 & 43.57 & 43.57 & 28.33 & 0.00000027 \\
\hline & temperature & 1 & 7.57 & 7.57 & 4.92 & 0.27590600 \\
\hline & area & 3 & 29.59 & 9.86 & 6.41 & 0.00035990 \\
\hline & cruise & 12 & 45.19 & 3.77 & 2.45 & 0.00535688 \\
\hline & Residuals & 202 & 310.70 & 1.54 & & \\
\hline & R-Square & & 0.29 & & & \\
\hline \multirow{6}{*}{$\begin{array}{l}\text { 1995-97 } \\
\text { all data }\end{array}$} & density & 1 & 79.83 & 79.83 & 57.32 & 0.00000000 \\
\hline & temperature & 1 & 14.89 & 14.89 & 10.69 & 0.00133559 \\
\hline & area & 3 & 78.72 & 26.24 & 18.84 & 0.00000000 \\
\hline & cruise & 2 & 7.71 & 3.85 & 2.77 & 0.06607837 \\
\hline & Residuals & 151 & 210.30 & 1.39 & & \\
\hline & R-Square & & 0.46 & & & \\
\hline \multirow{6}{*}{$\begin{array}{l}1995-97 \\
\text { densities } \\
<1\end{array}$} & density & 1 & 14.76 & 14.76 & 10.82 & 0.00143310 \\
\hline & temperature & 1 & 36.38 & 36.39 & 26.68 & 0.00000140 \\
\hline & area & 3 & 62.13 & 20.71 & 15.19 & 0.00000000 \\
\hline & cruise & 2 & 5.00 & 2.50 & 1.83 & 0.16594700 \\
\hline & Residuals & 90 & 122.74 & 1.36 & & \\
\hline & R-Square & & 0.49 & & & \\
\hline
\end{tabular}

stage which furthers the advantages of protandry by producing the largest females possible under the prevailing environmental constraints. It is reasonable to assume that a species which has evolved to make the largest individuals of the population females, would also have physiological mechanisms that ensured the current population of females was as large as possible.

Our results support the Charnov and Anderson (1989) conclusion that Pandalids have neither a fixed size or age at sex change. On the Scotian Shelf, the size at transition increased during a period of increasing growth rates, yet it remained high during a period of slower growth because the shrimp remained as males for an additional year's growth. Since growth to a larger size in crustaceans implies more molts, transition also cannot be related to a fixed number of instars. The question then arises, if not environmental cues, size, age, or instars, what determines sex change in Pandalids? Our data do not provide a definitive answer, but in view of the evidence and argument above, questions of what triggers sex change should be framed as follows: when does a male have to change sex? And, what is the minimum size that a female must be? Pandalus borealis is a cold water species. In northern areas growth is slow and females are larger after the transition simply because they are older. In warmer waters such as the Scotian Shelf and Gulf of Maine growth is unusually rapid and males would reach the hypothetical physiological male maturation threshold much earlier and at a smaller size, too small to function as females, hence a transitional "growth spurt" to achieve the minimum female size. From an evolutionary perspective, if we assume that protandry evolved from separate sexes, each with their own physiological thresholds for maturation, it is plausible that females would retain such a threshold. In this context, the appearance of primary females (i.e. animals which skip the male phase) in some southern areas (Shumway et al., 1985) can be viewed as regressive evolution to the original dioecious state because obligative early transition of males negates the benefits of protandry.

While the above discussion on what ultimately triggers sex change in Pandalids is speculative, our observations on the proximate causes, especially the influence of density and temperature, indicate that any observed changes in the size at sex transition must be interpreted carefully with regard to stock status. While a decrease in the size at transition may well indicate stock decline in some stocks under certain conditions, it is apparent that such a change can also indicate good or improving conditions. 




Fig. 9. A) Annual average sex ratio versus mean CL at transition for each shrimp fishing hole, 1982-88 and 1996-97, and B) sex ratio and mean size at transition for each fishing set of the two survey series.

\section{Acknowledgements}

We thank the captains and crews of RV E.E. Prince, MV Cody and Kathryn, MV Lady Megan and MV Miss Marie for their assistance during shrimp surveys. Michelle King and Michele Covey conducted sample analyses and data processing for the most recent surveys. Dr. Ian Perry and an anonymous reviewer provided many useful suggestions on the manuscript.

\section{References}

ALLEN, J.A. 1959. On the biology of Pandalus borealis Krøyer, with reference to a population off the Northumberland coast. J. Mar. Biol. Assoc. U.K., 38: $189-220$.

ARMSTRONG, M., S. CADRIN, J. IDOINE, C. MCBANE, D. MCCARRON, D. SCHICK, S. CLARK, and A. SCHICK. 1999. Assessment Report for Gulf of Maine Northern Shrimp, 1999. Report of the Atlantic States 
Marine Fisheries Commission Northern Shrimp Technical Committee, ASMFC, Washington D.C.

BERGSTRÖM, B. I. 1997. Do protandric pandalid shrimp have environmental sex determination? Marine Biology, 128: $397-407$.

CARPENTER, A. 1978. Protandry in the freshwater shrimp Pararya curvirostris (Heller, 1862) (Decapoda: Atyidae) with a review of the phenomenon and its significance in decapods. J. R. Soc. N.Z., 3(4): 343-358.

CHARNOV, E. L. and P. J. ANDERSON. 1989. Sex change and population fluctuations in pandalid shrimp. Am. Nat., 134: 824-827.

CHARNOV, E. L. 1979. Natural selection in pandalid shrimp: a test of a life history theory. Am. Nat., 113: $515-734$.

1981. Sex reversal in Pandalus borealis: effect of a shrimp fishery. Mar. Biol. Lett., 2: 53-57.

CHARNOV, E. L., D. GOTSCHALL, and J. ROBINSON. 1978. Sex ratio: adaptive response to population fluctuations in pandalid shrimp. Science, 200: 204206.

JENSON, A. J. C. 1967. The Pandalus borealis in the North Sea and Skagerak. Mar. Biol. Assoc. India, Proc. Symp. on Crustacea, Part IV, 1317-1319.
KOELLER, P. MS 1996. Aspects of the biology of northern shrimp (Pandalus borealis) on the Scotian Shelf. DFO Atl. Fish. Res. Doc., No. 9, 34 p.

2000. Relative importance of abiotic and biotic factors to the management of the northern shrimp (Pandalus borealis) fishery on the Scotian Shelf. J. Northw. Alt. Fish. Sci., 27: 21-33 (this volume).

KOELLER, P., M. COVEY and M. KING. MS 1996. The Scotian Shelf shrimp (Pandalus borealis) fishery in 1996. DFO Atl. Fish. Res. Doc., No. 128, 54 p.

MS 1997. The Scotian Shelf shrimp (Pandalus borealis) fishery in 1997. DFO Atl. Fish. Res. Doc., No. 125,51 p.

McCRARY, J.A. 1971. Sternal spines as a characteristic for differentiating between females of some Pandalidae. J. Fish. Res. Board Can., 28: 98-100.

SHUMWAY, E. S., H. C. PERKINS, D. F. SCHICK, and A. P. STICKNEY. 1985. Synopsis of biological data on the pink shrimp, Pandalus borealis Kroyer. NOAA Tech. Rep. NMFS 30/FAO Fisheries Synopsis, No. 144, $57 \mathrm{p}$.

WARNER, R. R. 1974. The adaptive significance of sequential hermaphroditism in animals. Am. Nat., 109: $61-82$. 